\title{
Decreasing trend in the strength of Tropical Easterly Jet during the Asian summer monsoon season and the number of tropical cyclonic systems over Bay of Bengal
}

\author{
B. R. Srinivasa Rao, D. V. Bhaskar Rao, and V. Brahmananda Rao ${ }^{1}$ \\ Department of Meteorology and Oceanography, Andhra University, Visakhapatnam, India \\ Received 25 February 2004; revised 21 April 2004; accepted 23 June 2004; published 21 July 2004.
}

[1] The NCEP/NCAR reanalysis data during the period 1958-1998 show a positive trend in the $100 \mathrm{hPa}$ zonal wind, decrease in the strength of Tropical Easterly Jet (TEJ) during the summer monsoon period of June through September. This is confirmed by the Radiosonde data. The number of observed Tropical Cyclonic Systems (TCS) over Bay of Bengal during the same period shows a decreasing trend. There is a strong negative correlation $(-0.549$ for the period $1958-1998,41$ years, significant at $99.9 \%$ level by a two sided student $t$ test) between the strength of TEJ and the number of Bay of Bengal TCS. This result has potential for long-range prediction of TCS, which is vital for the prediction of monsoon rainfall. INDEX TERMS: 3309 Meteorology and Atmospheric Dynamics: Climatology (1620); 3362 Meteorology and Atmospheric Dynamics: Stratosphere/troposphere interactions; 3374 Meteorology and Atmospheric Dynamics: Tropical meteorology. Citation: Rao, B. R. S., D. V. B. Rao, and V. B. Rao (2004), Decreasing trend in the strength of Tropical Easterly Jet during the Asian summer monsoon season and the number of tropical cyclonic systems over Bay of Bengal, Geophys. Res. Lett., 31, L14103, doi:10.1029/2004GL019817.

\section{Introduction}

[2] The establishment of strong easterlies in the upper troposphere over peninsular India is one of the important factors in the onset of southwest monsoon over India. The narrow belt of strong easterly winds is observed between 100 and $200 \mathrm{hPa}$ over southern periphery of India through out the southwest monsoon season (June through September). This is known as tropical easterly jet (TEJ) first observed by Koteswaram [1958]. The axis of this jet generally extends from $5-20^{\circ} \mathrm{N}$ during the southwest monsoon season over the Indian sub continent.

[3] Although some aspects of the TEJ and its connection with the monsoon are known, lack of persistent long-term data over the upper troposphere prevented a reliable measure of long-term trends of the TEJ. Not many papers have been written on the connection between the variations of the TEJ and several other aspects of monsoon such as the variability of number of monsoon depressions. Now with the availability of reliable homogeneous data such as that of

\footnotetext{
${ }^{1}$ Permanently at Center for Weather Prediction and Climate Studies (CPTEC), Instituto Nacional de Pesquisas Espaciais, Sao Jos dos Campos, Brazil.
}

Copyright 2004 by the American Geophysical Union. 0094-8276/04/2004GL019817\$05.00
NCEP/NCAR reanalysis, it is possible to discuss some aspects of the TEJ. Copious amounts of rainfall during the monsoon season are observed along the tracks of the westward moving depressions or low pressure systems over Bay of Bengal. During the 41 year period from 1958-1998, the total number (208) of Tropical Cyclone Systems (TCS) that are formed over north Indian ocean are essentially dominated by the number of cyclonic systems (178) that form over the Bay of Bengal out of which monsoon depressions (158) are the prominent ones in the summer monsoon season (June-September). The purpose of the present paper is to verify whether there are any long term fluctuations in the strength of the TEJ and whether these variations are connected to the number of cyclonic systems that form over the Bay of Bengal during the summer monsoon season.

\section{Data}

[4] Three data sets are used for this study. Monthly means of zonal wind at $100 \mathrm{hPa}$ for the months of June, July, August and September for the period of 1958-1998 NCAR/NCEP reanalysis data [Kalnay et al., 1996], number of tropical cyclone systems over Bay of Bengal for the same period from the published reports by the India Meteorological Department (IMD) [1979, 1996]; Indian Daily Weather Reports by IMD and upper air Radiosonde station data over an Indian station Trivandrum $\left(8.29^{\circ} \mathrm{N}\right.$, $76.57^{\circ} \mathrm{E}$ ) for the period $1964-1998$ from the "Monthly Climatic Data for the world" available with National Oceanic and Atmospheric Administration (NOAA), USA.

\section{Results}

[5] Figure 1a shows the distribution of mean zonal wind at $100 \mathrm{hPa}$ for 41 years $(1958-1998)$ during the monsoon period over the global tropics. The strength (around $30 \mathrm{~m} / \mathrm{s}$ ) and the extension of tropical easterly jet can be clearly seen. The composite of the $100 \mathrm{hPa}$ zonal wind anomalies for the low and high frequencies of TCS are presented in Figure $1 \mathrm{~b}$ and Figure 1c respectively. With the mean of the TCS for the period $1958-1998$ as 4.34 and standard deviation as 2.16 , the years of low (high) frequency are chosen as those with the number of cyclonic systems less than 3 (greater than 6). The composite anomaly for low frequency years (Figure 1b) show westerly (positive) anomaly with a magnitude of $2-3 \mathrm{~ms}^{-1}$ over peninsular India indicating a decrease in the strength of the TEJ. Correspondingly the composite anomalies for high frequency years (Figure 1c) show easterly (negative) anomaly of $1-2 \mathrm{~ms}^{-1}$ indicating 
(a)

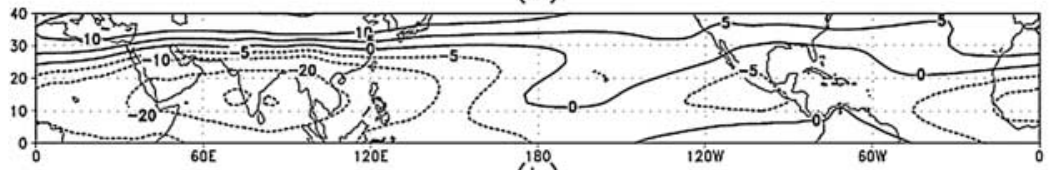

(b)

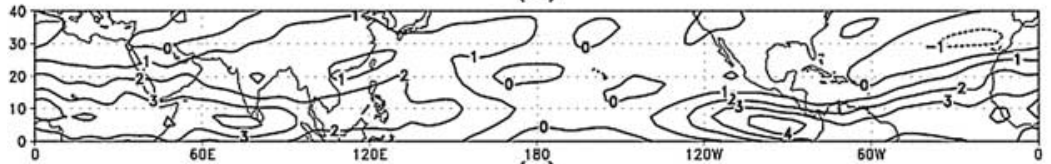

(c)

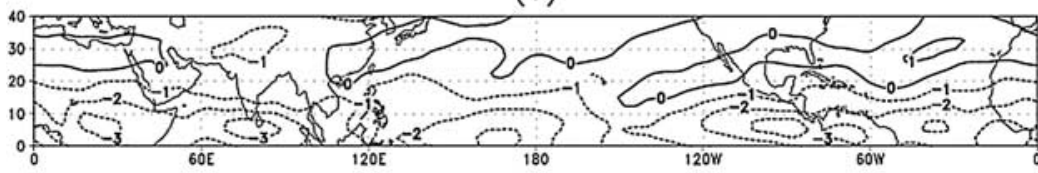

Figure 1. Distribution of $100 \mathrm{hPa}$ zonal wind $\left(\mathrm{ms}^{-1}\right.$ ) (a) 41 years mean for the period 1958-1998; (b) Composite of the anomalies for the years of low frequency (less than $3 \mathrm{TCS} /$ year) and (c) Composite of the anomalies for the years of high frequency (greater than $6 \mathrm{TCS} /$ year). (For Figure 1a contours are drawn at $5 \mathrm{~ms}^{-1}$ interval. Negative contours are hatched indicative of easterlies. For Figures $1 \mathrm{~b}$ and $1 \mathrm{c}$ contours are drawn at $0.5 \mathrm{~ms}^{-1}$. Positive/negative anomalies indicate westerly/easterly anomalies.).

increase of the strength of the TEJ over peninsular India. These composite anomalous circulation patterns corresponding to low (high) frequency of TCS clearly indicate their association with decrease (increase) of the strength of TEJ. To show the time progression of these anomalies Figure 2 is presented. This figure is the timelongitude section of zonal wind anomalies for the 41-year period at $10^{\circ} \mathrm{N}$ latitude of $100 \mathrm{hPa}$ as mentioned above. $100 \mathrm{hPa}$ is the level around which the tropical easterly jet

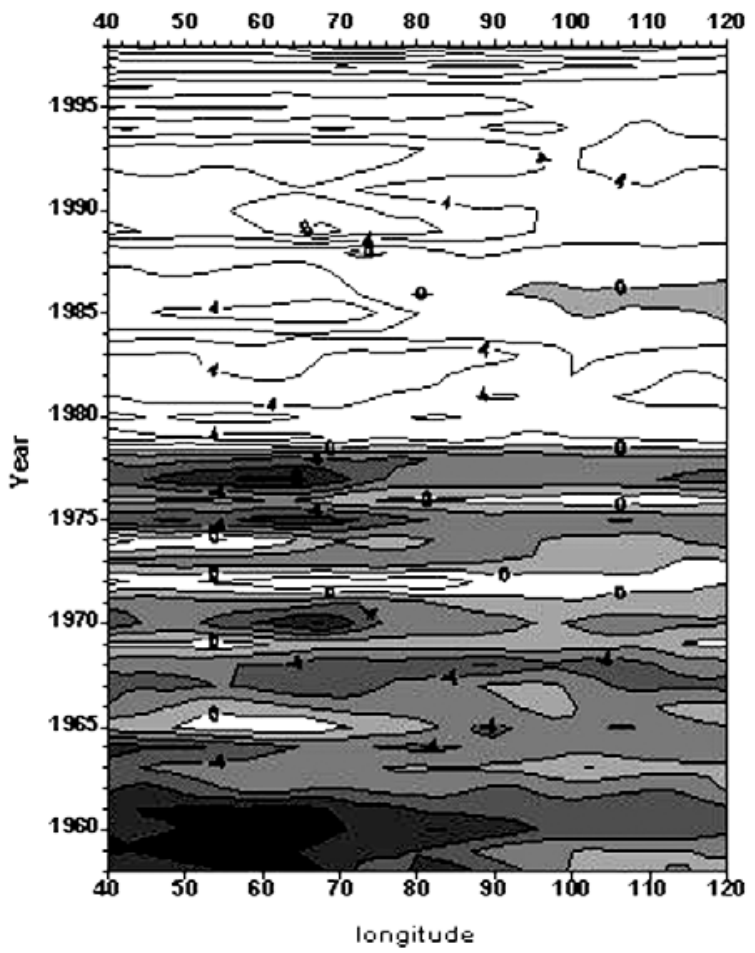

Figure 2. Time-Longitude section of zonal wind anomaly at $100 \mathrm{hPa}$ over $10^{\circ} \mathrm{N}$ (contour interval is $2 \mathrm{~ms}^{-1}$ and easterly anomaly region is shaded). has its maximum strength. From the figure a very clear positive trend over the 41 year period is seen i.e., the decrease in the strength of the TEJ. From about 1960 to 1978 easterly anomalies are noted and from about 1978 to 1997 westerly anomalies are seen. Another interesting feature about this variation is that the variability seems to be higher on the western side than on the eastern side.

[6] At this point the question that arises is whether the positive trend in the TEJ (easterly anomaly in the beginning and the westerly anomaly later) is real or an artifact of the NCEP/NCAR reanalysis data assimilation system. To answer this we use the Radiosonde data of an Indian station namely Trivandrum. Figure 3 shows the zonal wind anomalies of $100 \mathrm{hPa}$ at Trivandrum for the available 35 years (1964-98) and its five-year running mean along with NCEP/NCAR zonal wind anomalies (1958-1998). The five-year running mean confirms the positive trend of the TEJ during the later years. Also the yearly variation shows a clear positive trend from about 1977 to 1990. The correlation

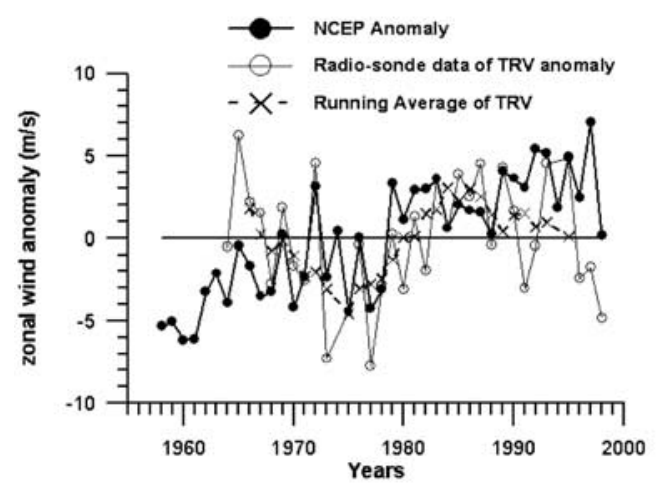

Figure 3. Anomaly of $100 \mathrm{hPa}$ zonal wind $\left(\mathrm{ms}^{-1}\right)$ of NCEP/NCAR data (1958-1998) averaged over the area $5-20^{\circ} \mathrm{N}$ and $40-100^{\circ} \mathrm{E}$; Anomaly of zonal wind at $100 \mathrm{hPa}$ at Trivandrum and 5 Year running average of zonal wind at Trivandrum (1964-1998). 


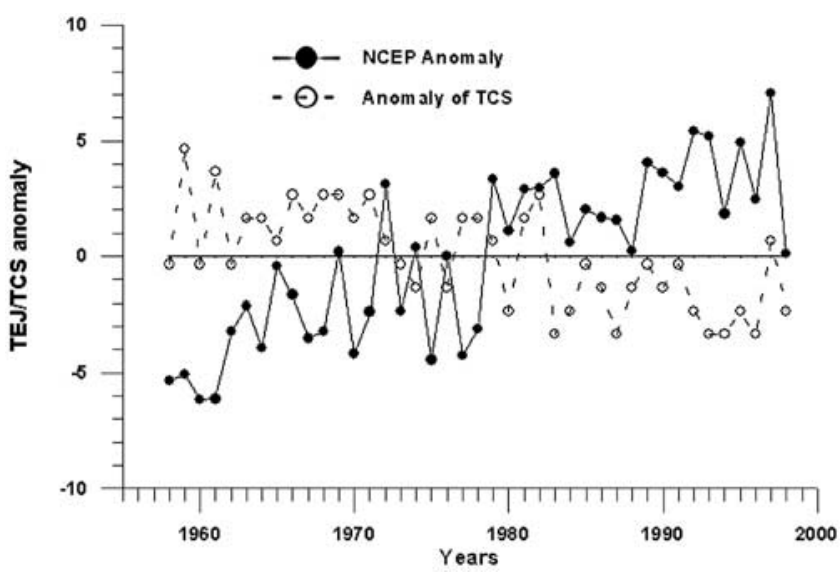

Figure 4. Time variation of zonal wind $\left(\mathrm{ms}^{-1}\right)$ anomaly at $100 \mathrm{hPa}$ of NCEP/NCAR (averaged over and the $5-20^{\circ} \mathrm{N}$ and $40-100^{\circ} \mathrm{E}$ ); Anomaly of number of Tropical Cyclonic Systems (TCS) over Bay of Bengal.

coefficient (CC) between the two series is +0.47 , which is significant at $99 \%$ level by a two sided student t test. It should be mentioned here that the data for Trivandrum are at an individual point while the data in the figure are the area averages. Thus a direct comparison in quantitative terms is not possible. However, the observed wind data at Trivandrum, which is the nearest Radiosonde station to the TEJ, confirms that the positive trend as observed in the NCEP/NCAR reanalysis data is real and not an artifact of the data assimilation system.

[7] There seems to be a connection between the number of TCS over Bay of Bengal during the monsoon period and wind shear. It would be interesting to verify how the long term variations of the TEJ over North Indian ocean is connected with the number of TCS. Figure 4 shows the NCEP/NCAR $100 \mathrm{hPa}$ zonal wind anomaly calculated as an area average over $5-20^{\circ} \mathrm{N}$ and $40-100^{\circ} \mathrm{E}$ over a mean of 41 years i.e., 1958 to 1998 for the 4 monsoon months JuneSeptember. In the same figure the dashed line shows the anomaly of number of TCS over Bay of Bengal. As mentioned earlier, the number of TCS over Bay of Bengal forms a large percentage $(85.5 \%)$ of the total TCS over North Indian Ocean. Figure 4 clearly shows the positive anomaly of TCS during the period 1958-1982 and negative anomaly during the latter period 1982-1998. The CC between two the curves is -0.549 , which is significant at $99.99 \%$ level. The correlation for the anomaly of TCS and the $100 \mathrm{hPa}$ anomaly zonal wind averaged over $5-20^{\circ} \mathrm{N}$ and $80-100^{\circ} \mathrm{E}$ (over Bay of Bengal) region is -0.525 , which is also significant at $99.99 \%$ level. Thus the TCS over Bay of Bengal have the strong negative correlation with the strength of the TEJ. Regarding the possible mechanism for the generation of monsoon depressions over Bay of Bengal, several authors [Shukla, 1977, 1978; Mishra and Salvekar, 1980; Moorthi and Arakawa, 1985; Aravequia et al., 1995] have suggested baroclinic instability of TEJ. These authors considered the baroclinic instability of the zonal wind with easterly shear associated with TEJ. They showed that higher (lower) wind shear leads to higher (lower) growth rates with or without the cumulus heating. Thus an increase (decrease) of the easterly shear in the earlier (latter) period as shown in Figure 4 leads to monsoon depressions with higher (lower) growth rates. Disturbances with weak growth rates may not sustain the frictional dissipation and may not develop. This may explain the decrease in the number of monsoon depressions when the shears are weak and increase when the shears are strong. In any case an actual calculation of growth rates is needed to verify this hypothesis.

[8] Gray [1968] indicated favorable environmental parameters conducive for tropical cyclogenesis. It will be of interest to examine the relation of the environmental factors such as low level cyclonic vorticity, atmospheric instability, mid-tropospheric humidity, low vertical wind shear and higher sea surface temperature. From the present analysis baroclinic instability seems to be an important factor and the role of other parameters will be taken up as a further study.

\section{Conclusions}

[9] From the above study the following conclusions can be made. The reanalysis data of NCEP/NCAR for the period 1958-1998 show positive trend with negative anomalies during the earlier period (1958-1978) and positive anomalies during the latter period (1978-1998) in the TEJ. This is confirmed by Radiosonde data. To our knowledge this is a new result not noted so far. It is also found that the number of tropical cyclone systems over Bay of Bengal (which forms about $85.5 \%$ of total cyclonic systems over north Indian ocean) shows a negative trend. The correlation coefficient between the variation of TCS over Bay of Bengal and the strength of TEJ is highly significant (at $99.99 \%$ level by two sided $t$ test) and negative. This shows that a decrease of the strength of TEJ leads to a decrease of the number of TCS. This result has the potential for the long-range prediction of the number of TCS during the south west monsoon season, which is vital for the long range prediction of monsoon rainfall over India and neighborhood.

\section{References}

Aravequia, J. A., V. B. Rao, and J. P. Bonatti (1995), The role of moist baroclinic instability in the growth and structure of monsoon depressions, J. Atmos. Sci., 52, 4393-4401.

Gray, W. M. (1968), A global view of the origin of tropical disturbances and storms, Mon. Weather Rev., 96, 669-700.

India Meteorological Department (IMD) (1979), Tracks of Storms and Depressions in the Bay of Bengal and Arabian Sea 1877-1970, New Delhi, India.

India Meteorological Department (IMD) (1996), Tracks of Storms and Depressions in the Bay of Bengal and Arabian Sea 1971-1990, New Delhi, India.

Kalnay, E., et al. (1996), The NCEP/NCAR 40 year reanalysis project, Bull. Am. Meteorol. Soc., 77, 437-471.

Koteswaram, P. (1958), Easterly jet stream in the tropics, Tellus, 10, 43-57. Mishra, S. K., and P. S. Salvekar (1980), Role of baroclinic instability in the development of monsoon disturbances, J. Atmos. Sci., 37, 383-394.

Moorthi, S., and A. Arakawa (1985), Baroclinic instability with cumulus heating, J. Atmos. Sci., 42, 2007-2031.

Shukla, J. (1977), Barotropic-baroclinic instability of mean zonal wind during summer monsoon, Pure Appl. Geophys., 115, 1449-1462.

Shukla, J. (1978), CISK barotropic-baroclinic instability and the growth of monsoon depressions, J. Atmos. Sci., 35, 495-508.

B. R. S. Rao, D. V. B. Rao, and V. B. Rao, Department of Meteorology and Oceanography, Andhra University, Visakhapatnam 530 003, India. (b_ravirao@yahoo.com) 